\title{
Quality Characteristics of Wheat Malts with Different Country of Origin and Their Effect on Beer Brewing
}

\author{
Yang Soo Byeon $\mathbb{D}^{1,2}$ Seung-Taik Lim $\mathbb{D}^{2},{ }^{2}$ Hyun-Jin Kim $\mathbb{D D}^{3}$ Han Sub Kwak ${ }^{1},{ }^{1}$ \\ and Sang Sook Kim (iD) \\ ${ }^{1}$ Research Group of Food Processing, Korea Food Research Institute, Wanju-gun 55365, Republic of Korea \\ ${ }^{2}$ Department of Biotechnology, College of Life Sciences and Biotechnology, Korea University, Seoul 02841, Republic of Korea \\ ${ }^{3}$ Division of Applied Life Sciences (BK21 Plus), Department of Food Science and Technology, Institute of Agriculture and Life \\ Science, Gyeongsang National University, 501 Jinjudaero, Jinju 52828, Gyeongsangnam-do, Republic of Korea
}

Correspondence should be addressed to Han Sub Kwak; hskwak@kfri.re.kr and Sang Sook Kim; sskim@kfri.re.kr

Received 8 April 2021; Accepted 13 May 2021; Published 27 May 2021

Academic Editor: Antimo Di Maro

Copyright (c) 2021 Yang Soo Byeon et al. This is an open access article distributed under the Creative Commons Attribution License, which permits unrestricted use, distribution, and reproduction in any medium, provided the original work is properly cited.

\begin{abstract}
The characteristics of wheat malt, wort, and beer from two Korean wheat varieties (Keumkang and Anzunbaengi; KM and AM, respectively) were compared to those of two commercial wheat malt controls from the USA and Germany (UM and GM), to examine the feasibility of Korean wheat for brewing. The quality parameters of four wheat malts, chemical properties of wort using them, volatile compounds, sensory attributes, and consumer acceptability of four final beers (KB, AB, UB, and GB) were analysed. Additionally, the relationship of each parameter was determined through multiple factor analysis. Korean wheat malts were different from control malts in free amino nitrogen (FAN), soluble and total nitrogen, and Kolbach index. The extract $(81.8-83.2 \%)$ and diastatic power $\left(407-477 \mathrm{WK}^{\circ}\right)$ of all samples were in the brewing field's recommended range. The FAN and yeast cell population of the wort samples were similar during fermentation except on the initial day, which showed a high FAN and yeast cell population for KM wort. Eleven volatile compounds with variable importance in projection scores above 1.0 were responsible for discrimination of the beer samples by partial least squares discriminant analysis. The four beer samples' overall acceptance scores were not significantly different. However, their acceptance trends were different depending on consumer preference segments by agglomerative hierarchical clustering analysis, implying the need for product development depending on the target consumer. Regarding sensory attributes, KB had a less fruity flavour than the other beer samples $(p<0.05)$ and sweetness of $A B$ tended to be higher than the others. An association plot based on multiple factor analysis of the wheat beer samples, volatile compounds, sensory properties, and overall acceptance showed that sweetness, alcohol aroma, and fruity flavour were closely associated with $\mathrm{AB}$ and overall acceptance, while 2,3-butanediol and turbidity were placed opposite side of there.
\end{abstract}

\section{Introduction}

Wheat beer is generally brewed with malted or unmalted wheat by substituting $40-60 \%$ barley malt [1]. It is mainly brewed by the top-fermentation process and has various aromatic characteristics, such as clove-like, banana-like, vanilla, and fresh fruit scents [2]. Wheat malt as a brewing material is still regarded as a specialty product, despite its long-term use as a malting material [3]. Recently, the popularity of wheat beer has been growing among beer consumers. A wider variety of high-quality flavourful beer has been created in response to the evolving tastes of consumers, as seen in the growth of the craft beer market [4].

For several years, as the demand for wheat beer has increased, finding a suitable wheat variety for utilization in beer making has been emphasized [5]. Some studies have been conducted to explore the appropriate wheat varieties for malting and brewing. Common wheat varieties grown in China [6] and Belgium [7] were investigated to identify suitable varieties for beer brewing by focusing on starch 
contents, foam stability, and haze intensity. From the standpoints of nonmainstream wheat cultivars, Benedetti et al. [8], Mayer et al. [9], and Marconi et al. [10] investigated the availability of hulled wheat, such as einkorn, emmer, and spelt, cultivated in Europe as materials for creating new beer styles. Furthermore, Bianco and Fancello [11] attempted to brew beer using Senatore Cappelli, which is a locally grown Italian durum wheat variety.

According to Korea Alcohol and Liquor Industry Association [12], beer is the most widely consumed alcoholic beverage in Korea, accounting for $38 \%$ of the market share of the alcoholic beverage industry in 2019. The domestic annual shipments of beer totalled approximately 2.0 billion litres [13]. However, domestic beer products have mainly been made from imported malts. The self-sufficiency rate for malt is very low, and most malt products are made primarily from imported products [14]. Domestic malt products are used by a few microbreweries. Recently, a few studies have attempted to replace imported malts with domestic malts, with interest in the utilization of domestic products [14-16]. However, information on beer production using Korean wheat or wheat malt is scarce.

Wheat varieties harvested in Korea, Keumkang, Baegjoong, and Jogyeong were substituted for imported wheat in Korean unfiltered rice wine (Makgeolli) [17, 18]. The authors of these studies reported that the physicochemical properties and consumer acceptability of Makgeolli were similar regardless of whether domestic or imported wheat was used. Byeon et al. [19] compared the characteristics of wheat malts made of three major Korean wheat varieties and commercial wheat malts imported from the USA and Germany. They focused on the malt quality and composition of their metabolites, indirectly suggesting the effect of wheat malt on beer quality.

The chemical and sensory properties of Korean wheat malt and beer might be useful information for small breweries that want to use Korean wheat malt or develop distinctive local beer products. However, this information has thus far been difficult to obtain. Therefore, the purpose of this study was to investigate the quality characteristics of wheat malt and beer made from Korean wheat varieties compared to those of beer from imported malt as the first brewing study with Korean wheat. The quality index of each malt-to-beer process was analysed, and the correlation between the parameters was also studied. The volatile compounds and consumer acceptability of finished beer were investigated to identify the differences among the beer samples. Additionally, the association of consumer liking with physicochemical properties of wheat malt and beer was investigated depending on consumer preference groups.

\section{Materials and Methods}

2.1. Wheat, Malting, Brewing, and Fermentation. The two Korean wheat varieties (Triticum aestivum L. var. Keumkang and Anzunbaengi) used for malting were harvested in 2018 in Jinju-si (geographic coordinates: $35^{\circ} 12^{\prime} \mathrm{N}, 128^{\circ} 07^{\prime} \mathrm{E}$ ) and Yeonggwang-gun (geographic coordinates: $35^{\circ} 17^{\prime} \mathrm{N}$, $126^{\circ} 17^{\prime} \mathrm{E}$ ), respectively, and they were purchased from local cooperatives. The Keumkang wheat is the major variety in
Korea and is classified as hard white winter wheat, and the Anzunbaengi is a native wheat variety in Korea characterised as a soft red winter wheat and semidwarf. These are widely grown in the south-eastern region of the Korean Peninsula.

The Korean wheat malts, which were made of variety Keumkang (KM) and Anzunbaengi (AM), were prepared using a micromalting system (MMSG, Custom Laboratory Products, Milton Keynes, UK). The wheat kernels (500 g) were steeped and germinated in perforated stainless steel germination cages at $15^{\circ} \mathrm{C}$. The malting process consisted of repeated wet and dry cycles (wet, dry, wet, dry, and wet: 19, 5, 19,4 , and $1 \mathrm{~h}$ ) followed by germination for $96 \mathrm{~h}$. After malting, the green malts were transferred to a kiln. The malt was dried at specific temperatures $\left(50^{\circ} \mathrm{C}\right.$ for $21 \mathrm{~h}, 60^{\circ} \mathrm{C}$ for $1 \mathrm{~h}, 70^{\circ} \mathrm{C}$ for $1 \mathrm{~h}$, and $80^{\circ} \mathrm{C}$ for $1 \mathrm{~h}$ ), and then, the rootlets and acrospires were manually removed from the dried malt. Because of difficulty in obtaining foreign whole wheat for wheat malting, two commercial wheat malts (white wheat malt, Briess Malt \& Ingredients Co., Chilton, WI, USA, and pale wheat malt, Weyermann Malting Co., Bamberg, Germany) purchased from online brewery product store (Seoul Homebrew, Seoul, Korea) were used as controls.

For brewing, each wheat malt as mentioned above and typical commercial Pilsner malt (Weyermann Malting Co., Bamberg, Germany) were used in a $1: 1$ ratio. They were ground using a roller mill (HKRS 75, Hankook Crusher Co., Ltd., Incheon, Korea) with a $1.5 \mathrm{~mm}$ gap. The brewing was performed using an automatic electronic brewing machine (BC-20L, Brewcascade, Incheon, Korea), which has a $20 \mathrm{~L}$ capacity. The barley $(2.3 \mathrm{~kg})$ and wheat $(2.3 \mathrm{~kg})$ malts were put into the brewing machine. For mashing, a common infusion method was used. The malting process was divided into 3 steps: $53^{\circ} \mathrm{C}$ for $20 \mathrm{~min}, 65^{\circ} \mathrm{C}$ for $60 \mathrm{~min}$, and $72^{\circ} \mathrm{C}$ for $10 \mathrm{~min}$. The temperature was increased at a rate of $1^{\circ} \mathrm{C}$ per minute for each step. After mashing, the wort was lautered for $30 \mathrm{~min}$ with additional sparging water $(5 \mathrm{~L})$ at $75^{\circ} \mathrm{C}$. The wort was boiled for $60 \mathrm{~min}$ with hop pellets. Hallertau Mittelfrueh hops $(28 \mathrm{~g})$ containing 4.0\% alpha acid (Joh Barth \& Sohn GmbH, Nuremberg, Germany) were added to the wort when it began to boil and $10 \mathrm{~min}$ prior to the end of the boiling period. The boiled wort was cooled to $20-25^{\circ} \mathrm{C}$. Approximately, $20 \mathrm{~L}$ of wort was then transferred into an HDPE bucket for fermentation. Pitching of the yeast was carried out at using liquefied yeast for top-fermentation (WLP 300, White Labs, San Diego, CA, USA). Fermentation was conducted at $20 \pm 1^{\circ} \mathrm{C}$ for 7 days in an incubator (HK-BI025, Hankuk S\&I Co. Ltd., Hwasung, Korea). After seven days of fermentation, the wort was transferred to $1 \mathrm{~L}$ three-layered plastic bottle for beer, and $7.5 \mathrm{~g}$ of refined sugar (CJ Cheiljedang Co., Ltd., Seoul, Korea) was added to generate $\mathrm{CO}_{2}$ in the beer. Secondary fermentation was conducted at $20 \pm 1^{\circ} \mathrm{C}$ in an incubator (HK-BI025, Hankuk S \& I Co. Ltd.) for 7 days. After the second fermentation, the wheat beers were matured for eight weeks in a refrigerator $\left(4 \pm 1^{\circ} \mathrm{C}\right)$. The beer samples were analysed at the end of maturation.

2.2. Wheat Malt Quality Parameters. The quality parameters of wheat malt samples were analysed using a congress wort made from micromashing in accordance with official 
Analytica-EBC methods [20]. The water content (\%; EBC 2.1), extract yield (\%; EBC 4.2), wort colour (EBC units; EBC 4.7.1), diastatic power ( $\mathrm{WK}^{\circ}$; $\left.\mathrm{EBC} 4.12\right)$, free amino nitrogen contents (FAN) $(\mathrm{mg} / 100 \mathrm{~g}$; EBC 4.10), soluble nitrogen contents (SN) (mg/L; EBC 4.3.1), total nitrogen levels (TN) (\%; EBC 4.9.1), and Kolbach index (KI) (\%; EBC 4.12) were measured. The viscosity was determined at $20^{\circ} \mathrm{C}$ using a rotational rheometer (MCR-102, Anton Paar, Graz, Austria) equipped with a parallel plate $(\varnothing 50 \mathrm{~mm})$. The viscosity was measured at the 50th point in kinematic viscosity data and was expressed as $\mathrm{mPa} \cdot \mathrm{s}$. All the tests were performed in triplicate.

2.3. Characteristics of Wort during Fermentation. The wort and beer samples were collected throughout the process as follows: initial day (D0), day 1 (D1), day 3 (D3), day 5 (D5), and day 7 (D7) of fermentation; last day of secondary fermentation (SF), and matured finished beer (FB). All the samples were centrifuged at $200 \mathrm{~g}$ for $10 \mathrm{~min}$, and the supernatants were used for the analysis. The reducing sugar content was mainly determined by the amount of monosaccharides $(\mu \mathrm{g} / \mathrm{mL})$ in the samples by the dinitrosalicylic acid method [21]. The ethanol concentration was measured according to AOAC (Association of Official Agricultural Chemists International) method 984.14 [22] using a chromatograph equipped with a flame ionization detector (7890A, Agilent Technologies Inc., Santa Clara, CA, USA) with an HP-FFAP column $(30 \mathrm{~m} \times 0.32 \mathrm{~mm}$ i.d. And $0.52 \mu \mathrm{m}$ film thickness). The yeast count was measured using YM Petrifilm (3 M Co., St Paul, MN, USA) according to the manufacturer's instructions. The number of yeast colonies was counted after $72 \mathrm{~h}$ of incubation at $25^{\circ} \mathrm{C}$ and was expressed as the log colony-forming unit per $1 \mathrm{~mL}$ of fermented wort $(\log \mathrm{CFU} / \mathrm{mL})$. The free amino nitrogen content (FAN; $\mathrm{mg} / \mathrm{L}$ ) was measured by the EBC method 4.10 [20].

2.4. Finished Beer Quality Parameters. As characteristics of $\mathrm{FB}$, the original extract, real extract, and apparent extract ( $\mathrm{OE}, \mathrm{RE}$, and $\mathrm{AE} ;{ }^{\circ} \mathrm{P}$ ) were measured by the $\mathrm{EBC}$ method 9.4 [20]. The OE, RE, and AE were calculated as specific gravity determinations at $20^{\circ} \mathrm{C}$ and were obtained from the wort for fermenting, the beer, and the residual beer after alcohol distillation, respectively. The apparent attenuation and real attenuation (AA and RA; \%) referred to the amount of sugar diminished by yeast action during fermentation and were calculated as follows:

$$
\begin{aligned}
& A A=\frac{(\mathrm{OE}-\mathrm{AE})}{\mathrm{OE}} \times 100, \\
& \mathrm{RA}=\frac{(\mathrm{OE}-\mathrm{RE})}{\mathrm{OE}} \times 100 .
\end{aligned}
$$

Additionally, the quality parameters of wheat malt samples were analysed using an Analytica-EBC method. The bitterness (IBU; EBC 9.8), beer colour (EBC units; EBC 9.6), and total polyphenol content (mg/L; EBC 9.11) were analysed [20]. The $\mathrm{pH}$ value was measured using a digital $\mathrm{pH}$ meter (Star A2115, Thermo Scientific Inc., Rockingham, $\mathrm{NH}$, USA). The titratable acidity (TA) was determined by titrating the boiled sample with sodium hydroxide until it reached a $\mathrm{pH}$ of 8.2 , according to Adadi et al.'s method [23]. The TA was expressed as the percentage of acetic acid $(\%, w / v)$.

\subsection{Identification of Volatile Compounds in Wheat Beer.} For the identification and quantification of volatile compounds in wheat beers, gas chromatography-mass spectrometry (GC-MS) (GC-2010 Plus, GCMS-TQ 8030, Shimazu Co., Tokyo, Japan) was used. The samples were sealed with two equivalents of dichloromethane (DCM) and ultrasonicated for 2 hours. The supernatant, i.e., the DCM layer, was separated for insertion into the GC injection port. Chromatographic separation was carried out using a GC system equipped with a DB-WAX column $(30 \mathrm{~m} \times 0.25 \mathrm{~mm}$ i.d. $\times 0.25 \mu \mathrm{m}$ film thickness; J\&W scientific, Santa Clara, CA, USA). The GC column was maintained at $40^{\circ} \mathrm{C}$ for $2 \mathrm{~min}$; the temperature was then increased at a rate of $11^{\circ} \mathrm{C} /$ $\min$ to $240^{\circ} \mathrm{C}$ and then maintained for $4 \mathrm{~min}$. The temperature of the injector was set at $230^{\circ} \mathrm{C}$, and helium carrier gas was flowed at $1 \mathrm{~mL} / \mathrm{min}$. The mass spectrometer was operated in Q3 scan mode at a voltage of $0.1 \mathrm{KV}$, and the ion source and interface temperatures were set at $230^{\circ} \mathrm{C}$ and $250^{\circ} \mathrm{C}$, respectively.

Identification of the volatile compounds detected by GCMS was performed on the basis of systematic matching with the reference mass spectra of the NIST 11 and Wiley 9.0 mass spectral libraries and retention indices. The concentrations of the volatile compounds were semiquantified using $n$-alkanes as an internal standard by comparing the peak area of each compound with the analysis of known mixtures.

2.6. Consumer Acceptability and Intensity of Sensory Attribute by Consumers. A total of 102 subjects (men $=43$ and women $=59$ ) aged between 20 and 60 years participated in the consumer test. Each consumer evaluated four beer samples brewed with different wheat malts in an individual sensory booth equipped with computerized sensory data collection software (Compusense Inc., Guelph, Canada) at the Korea Food Research Institute (Wanju-gun, Korea). The samples were coded with random 3-digit numbers, and the order of the sample presentation was randomized to minimize first-serving order bias. Each sample $(40 \mathrm{~mL})$ was presented in a transparent plastic cup $(65 \mathrm{~mL})$ in a monadic manner with a cracker (Carr's table water biscuits, Pladis Co., London, UK) and a cup of filtered water for palate cleansing. During testing, the beer samples were kept at $4 \pm 1^{\circ} \mathrm{C}$ by placing them in a container with ice and water. The consumers were asked to evaluate the acceptability of each sample (appearance, flavour, aroma, texture, and overall) using a 9-point hedonic $(1=$ dislike extremely, $5=$ neither like nor dislike, and $9=$ like extremely). The consumers were also asked to evaluate the intensity of sensory attributes, which were turbidity for appearance, sweet, citrus, alcohol, and yeast for aroma (A), sweet, sour and bitter for basic taste, alcohol, fruity and yeast for flavour 
(F), carbonation, body, and astringency for mouthfeel and overall aftertaste for aftereffect. The intensity of each sensory attribute was evaluated using a 10-point categorical scale ( 0 = none, $1=$ extremely weak, $5=$ neither weak nor strong, and 9 =extremely strong). Monetary compensation was provided to the consumers for their participation.

2.7. Statistical Analysis. Three replications of experiments were conducted for physicochemical characteristics of malt, wort, and beer samples. One-way analysis of variance (ANOVA) was conducted to determine the differences in physicochemical properties among the malt and beer samples, and the acceptability and sensory attributes among the beer samples. For the consumer test, the confidence level was set at $\alpha=0.10$, as in Guido et al. [24] and Vidal et al. [25]. When a significant difference among the samples was found, Tukey's multiple range test was applied to compare means at $p<0.05$. Agglomerative hierarchical clustering (AHC) analysis was conducted to segment the consumers into several groups by overall acceptability. The relationship between the characteristics of malt and beer samples was evaluated by the Spearman correlation test. Furthermore, multiple factor analysis (MFA) was performed to investigate the association among volatile compounds, sensory attributes, and overall consumer acceptance of the four beer samples. All the statistical analyses were conducted using XLSTAT statistical software (version 2019, Addinsoft Inc., Paris, France).

For statistical analysis of the processed GC-MS data set, SIMCA-P+ version 12.0.1 (Umetrics, Umeå, Sweden) was used and partial least squares discriminant analysis (PLSDA) was used to visualize the differences among the samples. The quality of the PLS-DA models was evaluated with $R^{2} X$ and $R^{2} Y$ (model fitness) and $Q^{2}$ (predictive ability) and was validated by permutation tests $(n=200)$. The volatile compounds contributing to the differences among the beer samples were found and identified based on their VIP values, which were calculated from the PLS-DA and ANOVA with Duncan's multiple range test $(p<0.05)$ using SPSS 17.0 (SPSS Inc., Chicago, IL, USA).

\section{Results and Discussion}

3.1. Malt Quality Parameter Analysis for Wheat Malts. The malt quality parameters for two Korean wheat malts (KM and AM) were compared with those for two commercial wheat malts imported from Germany (GM) and the USA (UM) (Table 1). The extract yields of the four malt samples were similar, ranging from 81.8 to $83.2 \%$. The colour of the congress wort was found to be in the range of 3.9-5.4 EBC units, indicating bright golden colour. The viscosity of the AM malt tended to be higher than that of the other samples, but no significant difference among the samples was found, and all the wheat malt samples used in this study were acceptable, considering the recommended viscosity for wheat malt $(<1.80 \mathrm{mPa} \cdot \mathrm{s})$ reported by Faltermaier et al. [5]. All malt samples were suitable for brewing, considering that the diastatic power of the four samples was higher than
$200 \mathrm{WK}^{\circ}$, which was reported to be the minimum required value for brewing by Bamforth [26].

The Korean wheat malts had significantly higher FAN contents than the imported wheat malts $(p<0.05)$. The FAN content of the KM malt $(140.0 \mathrm{mg} / 100 \mathrm{~g})$ was higher than that of the other malts, followed by the FAN content of the AM malt $(115.3 \mathrm{mg} / 100 \mathrm{~g})$. The $\mathrm{SN}$ was in the range of $792.6-978.5 \mathrm{mg} / 100 \mathrm{~g}$, and it is noteworthy that the SN of the Korean wheat malt was high. For the TN, the Korean wheat malts, KM (2.5\%) and AM (2.2\%), had significantly $(p<0.05)$ higher values than the control wheat malts, GB (1.9\%) and UB (1.7\%). Recently, similar results for Korean wheat malt were reported by Byeon et al. [19]. Briefly, the parameters related to nitrogen, such as FAN, SN, TN, and $\mathrm{KI}$, differed between the control wheat malts and the Korean wheat malts.

3.2. Properties of Wort during Fermentation. Four wort samples (GW, UW, KW, and AW), which contained 50\% different wheat malts as the main ingredients (GM, UM, $\mathrm{KM}$, and AM), were brewed at laboratory scales of $20 \mathrm{~L}$. To investigate the effects of the four different wheat malts on fermentative characteristics, the wort samples were prepared by an identical brewing process, which is exclusively used only for wheat malts.

The changes in the reducing sugar versus ethanol content and FAN content versus yeast cell population of the four wort samples during fermentation are shown in Figure 1. For the reducing sugar and ethanol concentrations, all of the wort samples showed similar trends during the entire fermentation period (Figure 1(a)). During the fermentation process, the ethanol concentration increased as the reducing sugar was depleted. All the beer samples in this study showed similar trends. These kinetic results indicated that four malt samples used in this study were similar in ethanol generation efficiency. On the other hand, regarding the FAN contents and yeast population (Figure 1(b)), among the wort samples, the FAN contents were the highest at D0 in the KW wort $(288.4 \mathrm{mg} / \mathrm{L})$; the other samples (GW, UW, and AW) had similar results, with FAN contents ranging from 226.3 to $246.3 \mathrm{mg} / \mathrm{L}$. The higher initial concentration of FAN in the KW could be caused by the Keumkang malt, which had a high nitrogen content (Table 1). The results of correlation analysis showed that FAN content of the wort before the incipient fermentation (at D0) had a positive correlation with malt properties related to nitrogen, such as FAN $(r=0.84)$, SN $(r=0.71)$, and TN $(r=0.85)$ of wheat malt, whereas KI of wheat malt showed negative correlated with FAN of wort $(r=-0.75)$ as in Table S1.

With ongoing fermentation, the minimum FAN content was observed on D5, and then similar concentrations were maintained until SF $(28.1-32.0 \mathrm{mg} / \mathrm{L})$ while the yeast cell populations were differed between the control (GW and UW) and Korean (KW and AW) wort samples in the early stage of fermentation. Nitrogen is an essential nutrient; appropriate levels should be provided to support the cellular components of Saccharomyces cerevisiae during anaerobic growth. However, yeast itself can produce amino acids by 
TABLE 1: Wheat malt quality parameters.

\begin{tabular}{|c|c|c|c|c|}
\hline & \multicolumn{2}{|c|}{ Control } & \multicolumn{2}{|c|}{ Korean wheat malt } \\
\hline & $\mathrm{GM}^{1}$ & UM & KM & $\mathrm{AM}$ \\
\hline Water content ${ }^{* * * 2}(\%)$ & $3.8 \pm 0.2^{\mathrm{b} 3}$ & $4.5 \pm 0.3^{\mathrm{a}}$ & $4.7 \pm 0.0^{\mathrm{a}}$ & $5.0 \pm 0.3^{\mathrm{a}}$ \\
\hline Extract $(\%)$ & $82.6 \pm 1.6$ & $83.2 \pm 1.3$ & $81.8 \pm 2.0$ & $82.3 \pm 1.0$ \\
\hline Color*** (EBC units) & $3.9 \pm 0.1^{\mathrm{b}}$ & $4.1 \pm 0.0^{\mathrm{b}}$ & $5.4 \pm 0.1^{\mathrm{a}}$ & $3.5 \pm 0.0^{c}$ \\
\hline Viscosity $(\mathrm{mPa} \cdot \mathrm{s})$ & $1.44 \pm 0.04$ & $1.47 \pm 0.12$ & $1.49 \pm 0.08$ & $1.63 \pm 0.14$ \\
\hline Diastatic power ${ }^{* * *}\left(\mathrm{WK}^{\circ}\right)$ & $407 \pm 5.2^{c}$ & $432 \pm 1.8^{\mathrm{b}}$ & $477 \pm 10.3^{\mathrm{a}}$ & $423 \pm 1.4^{\mathrm{b}}$ \\
\hline Free amino nitrogen ${ }^{* * *}(\mathrm{mg} / 100 \mathrm{~g})$ & $98.4 \pm 0.4^{\mathrm{c}}$ & $85.6 \pm 2.1^{\mathrm{d}}$ & $140.0 \pm 0.3^{\mathrm{a}}$ & $115.3 \pm 1.2^{\mathrm{b}}$ \\
\hline Soluble nitrogen ${ }^{* *}(\mathrm{mg} / 100 \mathrm{~g})$ & $866 \pm 29.3^{b c}$ & $793 \pm 15.6^{c}$ & $926 \pm 4.1^{\mathrm{ab}}$ & $979 \pm 73.0^{\mathrm{a}}$ \\
\hline Total nitrogen $* * *(\%)$ & $1.9 \pm 0.0^{c}$ & $1.7 \pm 0.0^{\mathrm{d}}$ & $2.5 \pm 0.1^{\mathrm{a}}$ & $2.2 \pm 0.0^{\mathrm{b}}$ \\
\hline Kolbach index** $(\%)$ & $46.0 \pm 1.6^{\mathrm{a}}$ & $46.5 \pm 0.5^{\mathrm{a}}$ & $37.8 \pm 1.2^{\mathrm{b}}$ & $44.0 \pm 3.2^{\mathrm{a}}$ \\
\hline
\end{tabular}

${ }^{1} \mathrm{GM}, \mathrm{UM}, \mathrm{KM}$, and AM represent German, USA, Keumkang, and Anzunbaengi wheat malt, respectively. ${ }^{2 * * *}$ and ${ }^{* *}$ indicate significant differences between samples at $p<0.001$ and $p<0.01$, respectively. ${ }^{3}$ Mean values of three replications. Values with different superscript letters within a row represent significant difference at $p<0.05$ by Tukey's multiple range test.

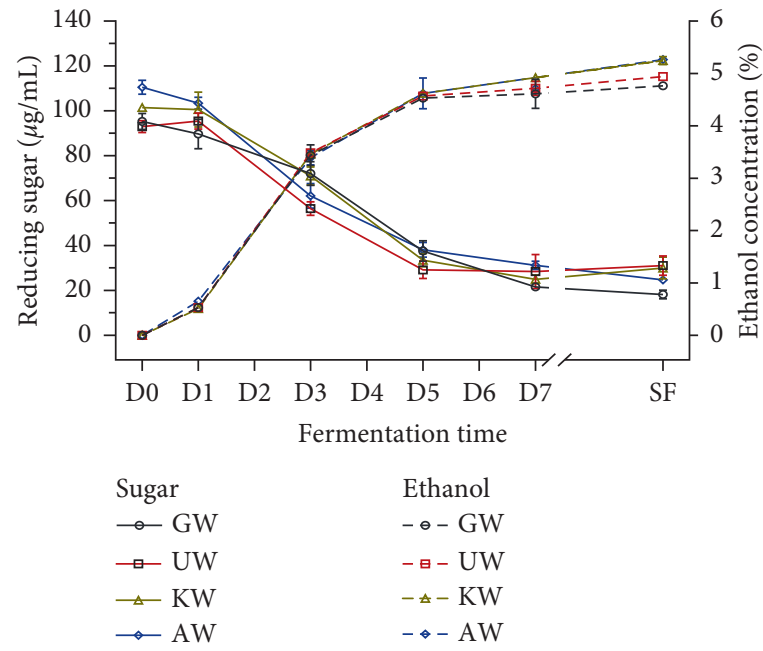

(a)

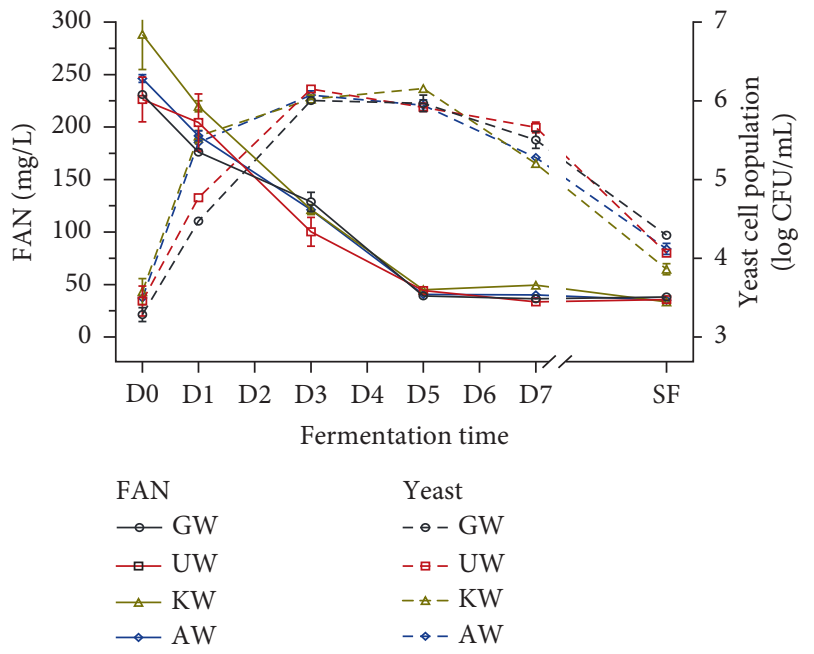

(b)

FIGURE 1: Changes of (a) reducing sugar and ethanol concentration and (b) free amino nitrogen (FAN) contents and yeast cell population among the wort samples during the fermentation. Four wort samples (GW, UW, KW, and AW) were made of four different wheat malts as the main ingredients (German, USA, Keumkang, and Anzunbaengi malt, respectively). Axis of abscissas points represents beginning for fermentation (D0), fermentation time of 1-7 days (D1-D7), and end of secondary fermentation (SF).

transamination and biosynthesis to meet its requirements for growth [27]. Therefore, constant level of FAN could be expected at the end of fermentation. The result of this study showed constant level of FAN after D5.

3.3. Physicochemical Characteristics of Wheat Beer. The physicochemical properties of finished beers (GB, UB, KB, and $A B$ ) from wort samples, GW, UW, KW and AW are in Table 2. The Korean wheat beers, $\mathrm{KB}$ (5.27\%) and $\mathrm{AB}$ (5.31\%), contained higher ethanol concentrations than the control wheat beers, GB (4.83\%) and UB (4.87\%). The real and apparent attenuation values were significantly $(p<0.05)$ higher for the Korean wheat beers $(\mathrm{KB}$ and $\mathrm{AB})$ than for the other beers (GB and UB). The attenuation value refers to the degree of conversion of sugars into alcohol and the creation of carbon dioxide by yeast [28]. For the four beer samples, the fermentation procedure was conducted with identical yeast types and fermentation conditions; therefore, the
Korean wheat beers showed higher attenuation than the other beers and better wort nutrient availability. In addition, the wort type explained the different alcohol concentrations shown in this study.

Bitterness was significantly lower in $\mathrm{KB}$ (8.9 IBU) than in the other beer samples $(p<0.05)$. The bitterness of beer is primarily determined by the isomerization reaction of $\alpha$-acids (humulones) derived from hops, but bitterness is also related to the polyphenols and proteins derived from the malt source $[29,30]$. The four beer samples were prepared under identical brewing procedures, including hop types and hopping times. The higher protein content found in KB might be related to the lower bitterness value.

The colour value of $\mathrm{KB}$ (7.3 EBC units) was significantly higher $(p<0.05)$ than those of the other beer samples, which were in the range of 6.8-6.9 EBC units. The high FAN content in the $\mathrm{KM}$, which was used for the $\mathrm{KB}$, might result in a beer with a high colour value due to the effect of the Maillard reaction [2]. 
TABle 2: Physicochemical characteristics of wheat beers.

\begin{tabular}{|c|c|c|c|c|}
\hline & \multicolumn{2}{|c|}{ Control } & \multicolumn{2}{|c|}{ Korean wheat beer } \\
\hline & $\mathrm{GB}^{1}$ & UB & $\mathrm{KB}$ & $\mathrm{AB}$ \\
\hline Ethanol $^{* * * 2}(\%)$ & $4.83 \pm 0.04^{\mathrm{b} 3}$ & $4.87 \pm 0.06^{\mathrm{b}}$ & $5.27 \pm 0.03^{\mathrm{a}}$ & $5.31 \pm 0.08^{\mathrm{a}}$ \\
\hline Original extract $\left({ }^{\circ} \mathrm{P}\right)$ & $12.3 \pm 0.1$ & $12.4 \pm 0.4$ & $12.5 \pm 0.4$ & $12.8 \pm 0.2$ \\
\hline Real extract $\left({ }^{\circ} \mathrm{P}\right)$ & $5.1 \pm 0.1$ & $5.1 \pm 0.4$ & $4.7 \pm 0.4$ & $4.9 \pm 0.2$ \\
\hline Real attenuation* (\%) & $58.9 \pm 0.7^{\mathrm{bc}}$ & $58.5 \pm 1.9^{c}$ & $62.1 \pm 1.9^{\mathrm{a}}$ & $61.7 \pm 1.2^{\mathrm{ab}}$ \\
\hline Apparent extract $\left({ }^{\circ} \mathrm{P}\right)$ & $3.5 \pm 0.1$ & $3.5 \pm 0.4$ & $3.0 \pm 0.4$ & $3.2 \pm 0.3$ \\
\hline Apparent attenuation* (\%) & $71.9 \pm 0.8^{\mathrm{bc}}$ & $71.4 \pm 2.3^{\mathrm{c}}$ & $75.8 \pm 2.4^{\mathrm{a}}$ & $75.4 \pm 1.5^{\mathrm{ab}}$ \\
\hline Bitterness (IBU) & $10.6 \pm 0.1^{\mathrm{a}}$ & $10.0 \pm 0.3^{\mathrm{a}}$ & $8.9 \pm 0.3^{\mathrm{b}}$ & $10.1 \pm 0.1^{\mathrm{a}}$ \\
\hline Color* (EBC units) & $6.9 \pm 0.2^{\mathrm{b}}$ & $6.8 \pm 0.1^{\mathrm{b}}$ & $7.3 \pm 0.1^{\mathrm{a}}$ & $6.8 \pm 0.1^{b}$ \\
\hline Polyphenols** (mg/L) & $123.6 \pm 4.3^{\mathrm{a}}$ & $102.8 \pm 13.9^{\mathrm{a}}$ & $89.2 \pm 3.2^{b}$ & $86.9 \pm 7.0^{\mathrm{b}}$ \\
\hline $\mathrm{pH}$ & $4.4 \pm 0.0$ & $4.3 \pm 0.0$ & $4.4 \pm 0.0$ & $4.3 \pm 0.0$ \\
\hline Total acidity $(\%, \mathrm{w} / \mathrm{v})$ & $0.41 \pm 0.04$ & $0.41 \pm 0.01$ & $0.42 \pm 0.02$ & $0.42 \pm 0.02$ \\
\hline
\end{tabular}

${ }^{1} \mathrm{~GB}, \mathrm{UB}, \mathrm{KB}$, and $\mathrm{AB}$ represent wheat beers made from grist containing $50 \%$ of wheat malt from German, USA, and Korean wheat variety (Keumkang and Anzunbaengi), respectively. ${ }^{2 * * *},{ }^{* *}$, and ${ }^{*}$ indicate significant differences between samples at $p<0.001, p<0.01$, and $p<0.05$, respectively. ${ }^{3}$ Mean values of three replications. Values with different superscript letters within a row represent significant difference at $p<0.05$ by Tukey's multiple range test.

Polyphenols in wort are known to interact with lipids and proteins during fermentation and are associated with the turbidity of beer and precipitation of insoluble sediment. The Korean wheat beer samples, $\mathrm{KB}$ and $\mathrm{AB}$, had polyphenol contents of 89.2 and $86.9 \mathrm{mg} / \mathrm{L}$, respectively, which were lower than those in GB $(123.6 \mathrm{mg} / \mathrm{L})$ and UB $(102.8 \mathrm{mg} / \mathrm{L})$. Mascia et al. [31] showed that the higher wheat protein content resulted in lower polyphenols in durum wheat beer. A similar trend was also shown in this study, which might be due to the differences in the amount of protein among the wheat malt samples.

The TA of the beer samples was in the range of $0.41-0.42 \% \mathrm{w} / \mathrm{v}$, and the $\mathrm{pH}$ ranged from 4.3 to 4.4 . The TA and $\mathrm{pH}$ of the beer samples were not affected by the wheat malt used. The $\mathrm{pH}$ of all the beer samples in this study was appropriate for common beer fermentation, i.e., in the range of 4.0-5.0, as described by Coote and Kirsop [32].

3.4. Volatile Compounds of Wheat Beer. Representative GCMS chromatograms of identified volatile compounds for the four wheat beers after eight weeks of maturation $(A B, G B$, $\mathrm{KB}$, and $\mathrm{UB}$ ) are shown in Figure 2. A total of 48 volatile compounds were identified by GC-MS. To visualize the differences among the beer samples, each peak intensity identified by GC was analysed using PLS-DA (Figure 3). The quality parameters of the PLS-DA plot were explained by $R^{2} X$ and $R^{2} Y$ (goodness of fit measures) and $Q^{2}$ (prediction accuracy). The $R^{2} X, R^{2} Y$, and $Q^{2}$ of the PLS-DA plot were $0.85,0.94$, and 0.86 , respectively, indicating good fitness and statistical acceptability. Cross validation was performed using 200 permutation tests (Figure 3(b)). The horizontal axis ( $t 1$ ) explained $51.6 \%$ of the total variation, and the vertical axis $(t 2)$ accounted for $14.0 \%$ of the total variation.

The four finished beer samples, GB, UB, KB, and $A B$, were discriminated from each other in the PLS-DA plot. Statistical analysis showed that 11 normalized volatile compounds significantly affected the differentiation of beer samples made from different malts $(p<0.001)$. Of these compounds, alcohols (1-propanol, isobutanol, isoamyl alcohol, methionol, and benzeneethanol), alkanes (dodecane, tetradecane, and eicosane), an ester (ethyl acetate), and other compounds (2,3-butanediol and 4-methylmannose) were identified as the major volatiles contributing to the discrimination of the beer samples. The above compounds might be the main contributors to the discrimination of the beer samples, considering that their VIP values were above 1.0. The box plot of individual volatile compounds affecting the discrimination of beer samples is presented in Figure 4.

Of the alcohols, especially isobutanol, isoamyl alcohol, and benzene ethanol, classified as higher alcohols, are the majority of volatile compounds in beer [33]. Among them, isobutanol and isoamyl alcohol were significantly higher in the Korean beers $(p<0.05), \mathrm{KB}(84.4$ and $206.4 \mathrm{mg} / \mathrm{L})$ and $\mathrm{AB}(74.7$ and $181.5 \mathrm{mg} / \mathrm{L})$, than in the two control beers, GB (63.9 and $170.4 \mathrm{mg} / \mathrm{L})$ and $\mathrm{UB}(61.0$ and $157.9 \mathrm{mg} / \mathrm{L})$ (Figure 4). Isobutanol and isoamyl alcohol are produced by the decarboxylation and reduction of $\alpha$-keto acids derived as amino acid metabolism by yeast action, and their presence depends on the nutrient composition of the wort [34, 35]. High concentrations of isobutanol and isoamyl alcohol in the Korean wheat beers might be influenced by the high content of branched amino acids derived from the AM and $\mathrm{KM}$, considering the high concentration of branched amino acids in Korean malts, as Byeon et al. [19] reported. Isobutanol and isoamyl alcohol are associated with the beer sensory descriptions of bitterness and alcohol flavour. The difference in their concentrations suggested a difference in the sensory characteristics of the Korean wheat beers and control beers due to the use of a different malt. Benzeneethanol content was significantly different among the samples $(p<0.05)$; its content was higher in $\mathrm{KB}$ than in the other beers. This may be because of the concentration of phenylalanine derived from KM during mashing. Benzeneethanol is commonly found in various alcoholic beverages, and its sensory descriptor is a floral aroma [36, 37]. Methionol is an organosulphur compound that can be found in diverse foods and beverages and contributes a characteristic flavour. In terms of beer production, volatile methionol is generally found at a higher content in topfermented wheat beer than in lager beer or Pilsner beer [38]. The sensory description of methionol is sweet, raw potato, 


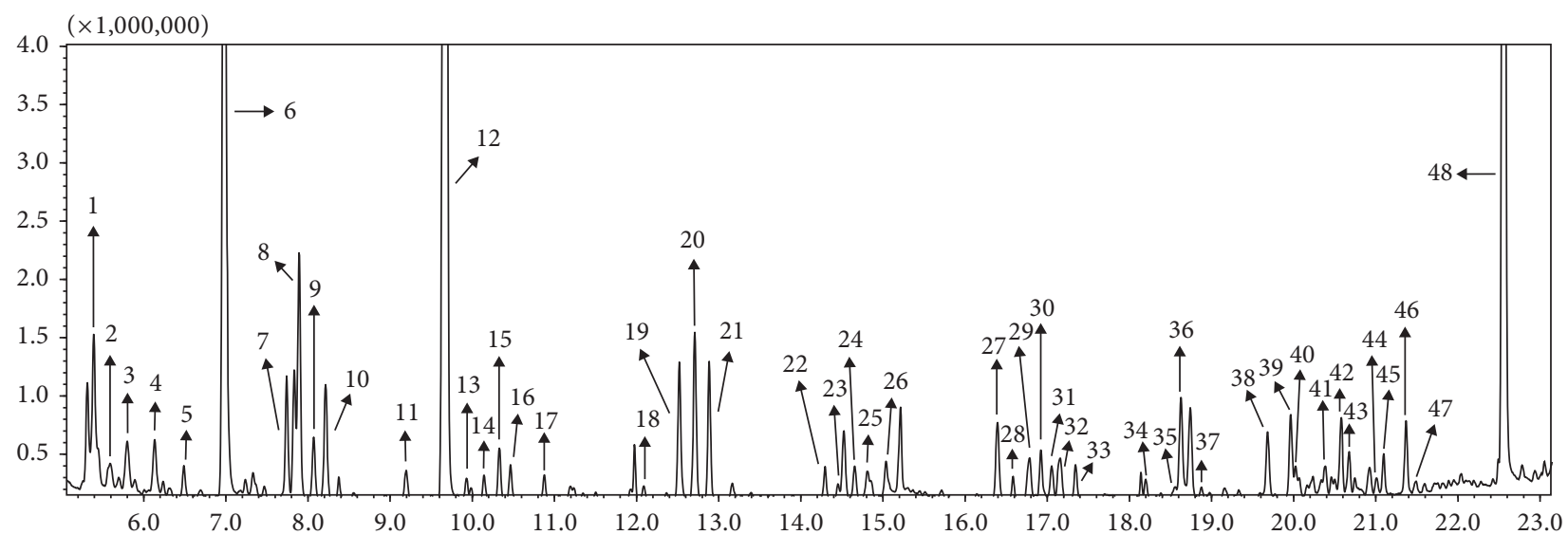

FIGURE 2: Representative gas chromatography-mass spectrometry (GC-MS) chromatogram of identified volatile compounds from wheat beers. (1) phosphorous acid, (2) tetrachloroethylene, (3) 1-propanol, (4) 4,6-dimethyldodecane, (5) 3,7-dimethyl-1-octene, (6) 2-methyl-1propanol, (7) 2,4-diethyl-1-heptanol, (8) isoamyl acetate, (9) 1,2-dimethylbenzene, (10) 1,2-dimethylbenzene, (11) 1,2-dimethylbenzene, (12) isopentyl alcohol, (13) dodecane, (14) 4,6-dimethyldodecane, (15) 4,6-dimethyldodecane, (16) 4,6-dimethyldodecane, (17) 8-methylheptadecane, (18) dodecyl nonyl ether, (19) 2,4-diethyl-1-heptanol, (20) 2,4-diethyl-1-heptanol, (21) 2,4-diethyl-1-heptanol, (22) tetradecane, (23) hexadecane, (24) hexadecane, (25) docosanoic acid, ethyl ester, (26) hexadecane, (27) 2,3-butanediol, (28) octyl tetracosyl ether, (29) heptacosyl trifluoroacetate, (30) tridecanol, (31) 2,3-butanediol, (32) tridecanol, (33) tridecanol, (34) heneicosane, (35) 1methoxy-2-butanol, (36) 3-methylbenzaldehyde, (37) eicosane, (38) 3-(methylthio)-1-propanol, (39) acetic acid, ethyl ester, (40) tridecanol, (41) nonadecyl pentafluoropropionate, (42) 2-hexyl-1-decanol, (43) 2-hexyl-1-decanol, (44) 4-methylmannose, (45) 2-hexyl-1-decanol, (46) 2-phenylethyl ester acetic acid, (47) heneicosane, and (48) benzeneethanol.

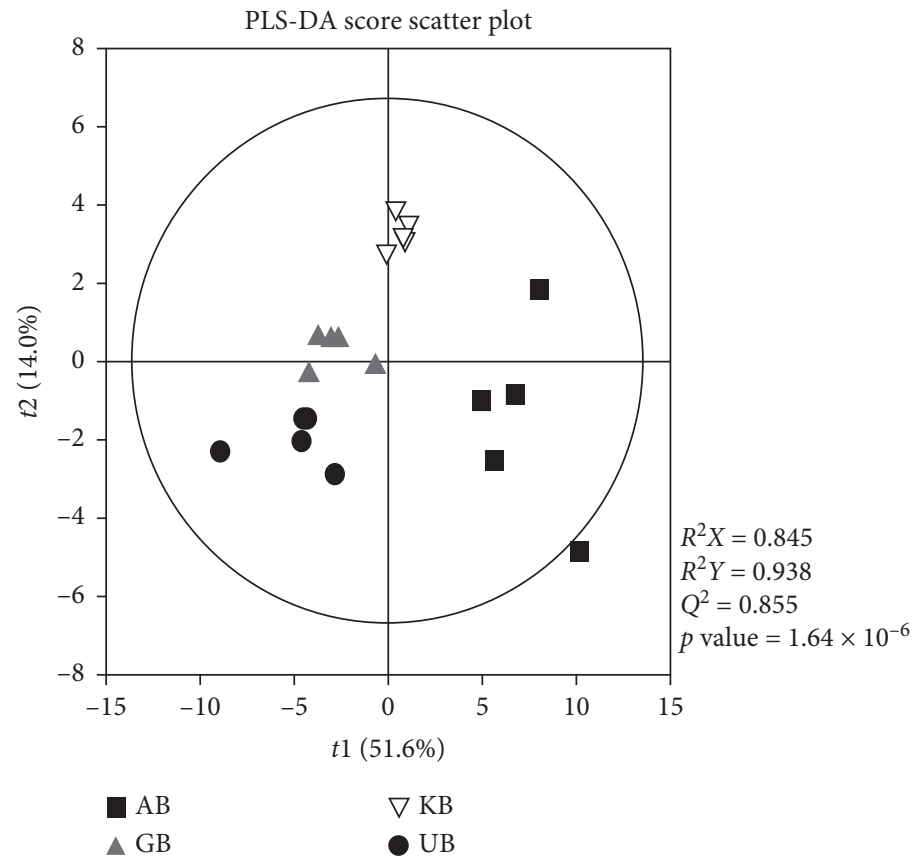

(a)

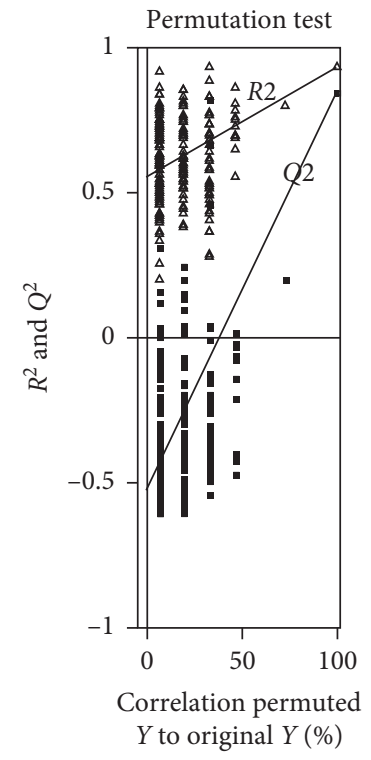

(b)

FIGURE 3: (a) PLS-DA score plot of volatile compounds obtained from GC-MS analysis of four wheat beer from grist containing $50 \%$ wheat malts. (b) The quality of PLS-DA score plots was evaluated using $R^{2} X, R^{2} Y, Q 2$, and $p$ values and the permutation test validated by 200 times. $\mathrm{GB}, \mathrm{UB}, \mathrm{KB}$, and $\mathrm{AB}$ represent wheat beers made of grist containing $50 \%$ of wheat malt from German, USA, and Korean wheat variety (Keumkang and Anzunbaengi), respectively.

and oiled cabbage, and its perception threshold was reported to be $0.5-2.0 \mathrm{ppm}$ in common beer $[39,40]$. These flavouractive compounds could be indicators of an off flavour when present in concentrations exceeding the odour threshold [40]. The methionol content in beer has been known to be affected by the L-methionine content in wort. A higher methionol content was found in $\mathrm{KB}$ than in the other beers in this study. This is probably because $\mathrm{KB}$ was made from $\mathrm{KM}$, which had a high methionine concentration. This was confirmed in a previous Korean wheat malt study described 


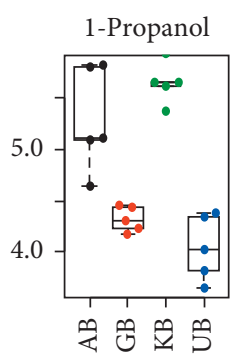

(a)

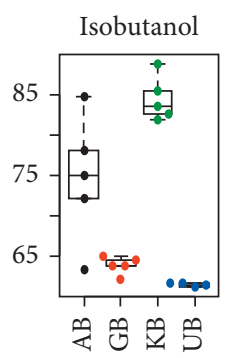

(b)

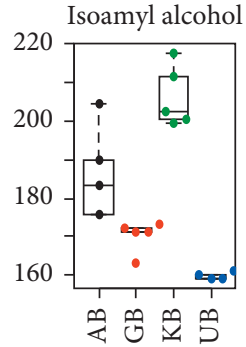

(c)

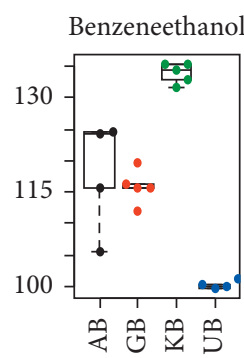

(d)

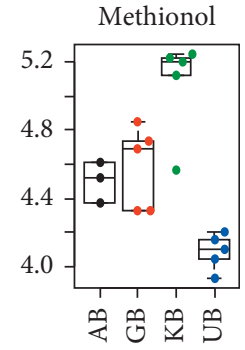

(e)

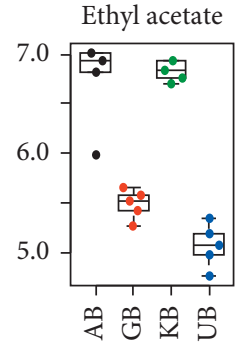

(f)

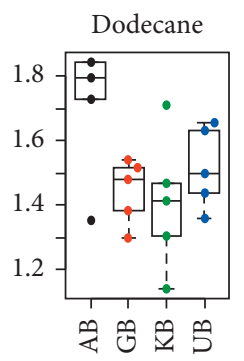

(g)

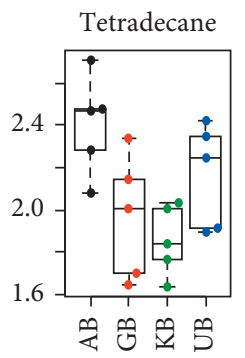

(h)

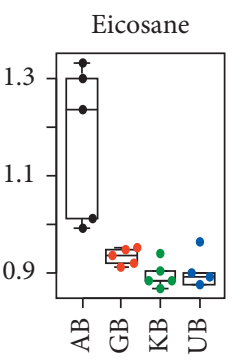

(i)

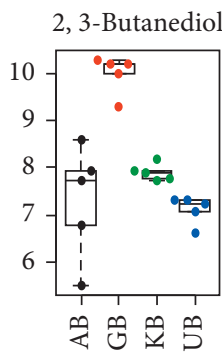

(j)

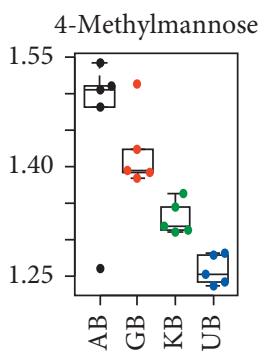

(k)

FIGURE 4: Box plot of volatile compounds affecting discrimination of beer samples. GB, UB, KB, and AB represent wheat beers made of grist containing $50 \%$ of wheat malt from German, USA, and Korean wheat variety (Keumkang and Anzunbaengi), respectively.

by Byeon et al. [19], which showed that Keumkang malt had a high methionine content.

Esters are produced by brewing yeast, and the reaction between conjugated esters of organic acids and alcohols plays an important role in beer flavour characteristics [33]. Ethyl acetate has been reported to give a fruity flavour to beer [41], and its perception threshold is known to be relatively high, at 20-30 mg/L. These compounds would have a minor influence on beer flavour, although they are quantitatively the most prominent compounds among the esters. The volatile compounds found in the beer samples in this study were thought to contribute to the discrimination of the beer samples, with a VIP value of 1.1 in the PLS-DA model. The concentrations were significantly higher in $\mathrm{AB}(6.8 \mathrm{mg} / \mathrm{L})$ and $\mathrm{KB}(6.9 \mathrm{mg} / \mathrm{L})$ than in $\mathrm{GB}(5.5 \mathrm{mg} / \mathrm{L})$ and $\mathrm{UB}(5.1 \mathrm{mg} / \mathrm{L})$; however, they were below the detectable range in all the beer samples. The volatile alcohols and esters derived in this study, 1-propanol, isobutanol, isoamyl alcohol, benzeneethanol, methionol, and ethyl acetate, had a positive correlation with both reducing sugar and FAN in wort $(r=0.67-0.89)$ (Table S1).

More volatile hydrocarbons, such as dodecane, tetradecane, and eicosane, were detected in $\mathrm{AB}$ than in the other beers. The results of the PLS-DA model suggest that these compounds might have played an important role in distinguishing the samples. These hydrocarbons had a positive correlation with reducing sugar in D0 wort: dodecane $(r=0.73)$, tetradecane $(r=0.63)$, and eicosane $(r=0.61)$ (Table S1). However, the role of hydrocarbons in beer properties has not been previously studied; thus, further investigations are necessary to confirm the relationship between hydrocarbons and reducing sugar or sensory properties.

2,3-Butanediol is converted from diacetyl (2,3-butanedione) via acetoin during the maturation period, which is the period following the main fermentation [33]. Diacetyl occurs as an intermediate by-product when yeast biosynthesizes amino acids, particularly leucine and valine, by itself. The GB sample had a higher 2,3-butanediol content than the other beer samples $(p<0.05) .2,3$-Butanediol has been reported to be a flavour-active compound, with bitterness, acidic, and pungent flavours in various alcoholic beverages, such as fermented wine and liquor. Recently, Heo et al. [42] reported that in the Korean liquor, i.e., yakju, the volatile compound 2,3-butanediol was associated with dislike among young consumers. However, the impact of 2,3butanediol on beer flavour was regarded as meaningless, since its content in the beer samples was far below the threshold.

3.5. Consumer Acceptability. The results of the consumer acceptability test of the beer samples are shown in Table 3. The mean ratings of the overall acceptance were not significantly different among the samples and were in the range of 5.63-6.08. The results showed that the beers made using Korean wheat malts were not inferior to the wheat beers made from commercial standard wheat malts. The acceptability for appearance was significantly $(p<0.05)$ lower in $\mathrm{GB}$ than in the Korean wheat beer samples (KB and $\mathrm{AB}$ ). The acceptability for flavour was different among the beer samples at $p<0.10$. Generally, the flavour acceptability for $\mathrm{AB}$ and $\mathrm{GB}$ was similar, and it was higher than that for $\mathrm{KB}$.

Using only mean values of all the consumers might result in distorted or misleading results, owing to latent information associated with the consumers, as Kwak et al. [43] reported. AHC analysis was used to segment the consumers into homogeneous groups of individuals based on individual preferences. Three distinctive consumer segments were identified by AHC analysis based on overall acceptability 
TABle 3: Consumer $(n=102)$ acceptability of wheat beer samples.

\begin{tabular}{lcccc}
\hline & & Control & & \multicolumn{2}{c}{ Korean wheat beer } \\
& $\mathrm{GB}^{1}$ & $\mathrm{UB}$ & $\mathrm{KB}$ & $\mathrm{AB}$ \\
\hline Overall acceptance $_{\text {Appearance*3 }}^{* * 92 \pm 1.51^{2}}$ & $5.92 \pm .08 \pm 1.48$ \\
Aroma & $5.68 \pm 1.50^{\mathrm{b}}$ & $5.84 \pm 1.55$ & $5.63 \pm 1.80$ & $6.10 \pm 1.41^{\mathrm{a}}$ \\
Flavour $^{*}$ & $5.89 \pm 1.44$ & $5.87 \pm 1.37^{\mathrm{ab}}$ & $5.70 \pm 1.47$ & $6.25 \pm 1.28^{\mathrm{a}}$ \\
Texture & $6.05 \pm 1.52^{\mathrm{a}}$ & $5.89 \pm 1.43$ & $5.57 \pm 1.71^{\mathrm{b}}$ & $6.12 \pm 1.33$ \\
\hline
\end{tabular}

${ }^{1} \mathrm{~GB}, \mathrm{UB}, \mathrm{KB}$, and $\mathrm{AB}$ represent wheat beers made from grist containing $50 \%$ of wheat malt from German, USA, and Korean wheat variety (Keumkang and Anzunbaengi), respectively. ${ }^{2}$ Mean \pm standard deviation values by 102 consumers, respectively; $1=$ dislike extremely, $5=$ neither like nor dislike, and $9=$ like extremely. ${ }^{3 * *}$ and ${ }^{*}$ indicate significant differences between samples at $p<0.01$ and $p<0.05$, respectively. ${ }^{4}$ Values with different superscript letters within a row represent significant difference at $p<0.05$ by Tukey's multiple range test.

(Table 4): cluster 1 (CL1) with 30 subjects; cluster 2 (CL2) with 43 subjects; and cluster 3 (CL3) with 29 subjects. In CL1, KB (3.47) had the lowest overall acceptance, while UB (6.23) had the highest overall acceptance among the four beer samples $(p<0.05)$. The overall acceptance scores for the four wheat beer samples were higher than 6.0 in CL2, indicating that CL2 might be a group of wheat beer lovers. In CL3, UB had a lower acceptance score than the other beers. When looking at the acceptability scores of the three clusters, $A B$ was in the range of 5.21-6.91, suggesting that $A B$ is generally well accepted by consumers, regardless of cluster. On the other hand, KB showed distinctly different tendencies in acceptability depending on cluster, with overall acceptance scores of 3.47 in CL1 and 7.14 in CL2.

3.6. Sensory Attributes by Consumer Perceptions. The intensity of the sensory attributes reported by the consumers for the wheat beers is shown in Figure 5. For the appearance of the beer samples, turbidity was significantly $(p<0.05)$ higher in GB (4.7) than in $\mathrm{AB}$ (3.9); considering the overall acceptance mean scores for $\mathrm{GB}$ and $\mathrm{AB}$, this suggests that consumers did not prefer samples with high turbidity. The alcohol aroma was significantly different across the samples $(p<0.10)$ and was highest in $A B$ (3.9), which was related to this beer having the highest ethanol concentration (5.3\%) (Table 2). Sweetness was higher in $\mathrm{AB}$ than in $\mathrm{UB}$ or $\mathrm{KB}$. However, the influence of sweetness might be relatively weak, considering that the intensity was below 4 on a 9-category scale. KB had less of a fruity flavour than the other beer samples $(p<0.05)$.

This could result from the concentration of the volatile compounds present in the beer samples being below the thresholds. Even though carbonation was higher in KB than in the other beer samples, there was no significant difference among the four beer samples in mouthfeel (carbonation, body, and astringency) or overall aftertaste. Generally, the sensory characteristics of the Korean wheat beer samples $(\mathrm{KB}$ and $\mathrm{AB})$ were similar to those of the control beer samples (GB and UB), except for turbidity. $A B$ had lower turbidity than the other beer samples in this study, while the highest turbidity was found in GB.

3.7. Relationship among the Volatile Compounds, Sensory Attributes, and Overall Acceptability of Wheat Beers by MFA. For the MFA, a correlation map of 11 volatile compounds, 15 sensory attributes, and the overall acceptance by each cluster (determined by AHC) and all the consumers is given in Figure 6(a) and that of the four wheat beer samples is given in Figure 6(b). The 11 volatile compounds in the MFA were selected because they had VIP scores $>1.0$. A total of $80.5 \%$ of the variance was explained by F1 (53.7\%) and F2 (26.8\%).

Overall, hydrocarbons (eicosane, dodecane, and tetradecane) were plotted on the positive side of F1, while most flavour-active compounds, such as higher alcohols (benzeneethanol, isoamyl alcohol, and methionol) and an ester (ethyl acetate), were plotted on the negative side of F1. Sweetness, sweet_A, alcohol_A, citrus_A, fruit_F, and carbonation variables were plotted in quadrant 1 . On the other hand, bitterness was located in quadrant 2 , which contrasted well with yeast_A and sourness, which were located in quadrant 4.

The overall acceptance by all the consumers (OA_total, $n=102)$ was plotted in quadrant 1 , alongside OA_CL1 $(n=30)$, on the positive side on F1, while CL2 $(n=43)$ and CL3 $(n=29)$ were in quadrant 2 , on the opposite side of the horizontal axis. As mentioned before, ethyl acetate is known to reflect fruity notes [41]; however, fruity notes, such as a citrus_A and fruity_F, were not closely related to ethyl acetate in this correlation map. This finding might be explained by an ethyl acetate threshold that is too low to allow its recognition, which is commonly $20-30 \mathrm{mg} / \mathrm{L}$ in beer. 2,3-Butanediol was positively related to alcohol_F, astringent, and turbidity in the correlation map, and it was plotted opposite from OA_total. According to this plot, 2,3butandial might have a negative impact on acceptability, and Heo et al. [42] showed a similar trend in alcoholic beverage samples.

Methionol was closely related to yeast_F, and among the four beer samples, KB was closely related to yeast_F, as shown in Figure 5(a). Additionally, KB was plotted opposite of OA_CL1 and carbonation. KB was the least liked beer sample by CL1. This could be because KB had the least carbonation among the beer samples, considering the close relationship between $\mathrm{OA}$ and carbonation for CL1 (Figure 5). On the other hand, OA_CL2 and OA_CL3 showed associations with bitterness, yeast_F, aftertaste, and body. As shown in the MFA correlation map, OA_CL2 and OA_CL3 were positioned close to each other, and they were plotted on the opposite side as UB. In particular, for CL3, UB was the least liked sample among the four beer samples. 
TABLE 4: Overall acceptance for four beer samples depending on preference segments by agglomerative hierarchical cluster analysis (AHC).

\begin{tabular}{lcccc}
\hline & & Control & & \multicolumn{2}{c}{ Korean wheat beer } \\
& $\mathrm{GB}^{1}$ & $\mathrm{UB}$ & $\mathrm{KB}$ & $\mathrm{AB}$ \\
\hline Total $(n=102)$ & $5.92 \pm 1.51^{2}$ & $5.84 \pm 1.55$ & $5.63 \pm 1.80$ & $6.08 \pm 1.48$ \\
Cluster $1^{* * 3}(n=30)$ & $5.37 \pm 1.67^{\mathrm{b} 4}$ & $6.23 \pm 1.45^{\mathrm{a}}$ & $3.47 \pm 1.01^{\mathrm{c}}$ & $5.73 \pm 1.55^{\mathrm{ab}}$ \\
Cluster 2 $^{*}(n=43)$ & $6.49 \pm 1.44^{\mathrm{b}}$ & $6.53 \pm 1.20^{\mathrm{b}}$ & $7.14 \pm 0.83^{\mathrm{a}}$ & $6.91 \pm 0.92^{\mathrm{ab}}$ \\
Cluster 3 $^{* * *}(n=29)$ & $5.66 \pm 1.17^{\mathrm{a}}$ & $4.41 \pm 1.15^{\mathrm{b}}$ & $5.62 \pm 1.01^{\mathrm{a}}$ & $5.21 \pm 1.47^{\mathrm{a}}$ \\
\hline
\end{tabular}

${ }^{1} \mathrm{~GB}, \mathrm{UB}, \mathrm{KB}$, and $\mathrm{AB}$ represent wheat beers made from grist containing $50 \%$ of wheat malt from German, USA, and Korean wheat variety (Keumkang and Anzunbaengi), respectively. ${ }^{2} \mathrm{Mean} \pm$ standard deviation values by consumers; $1=$ dislike extremely, $5=$ neither like nor dislike, and $9=$ like extremely. ${ }^{3 * * *}$ and ${ }^{*}$ indicate significant differences between samples at $p<0.001$ and $p<0.05$, respectively. ${ }^{4}$ Values with different superscript letters within a row represent significant difference at $p<0.05$ by Tukey's multiple range test.

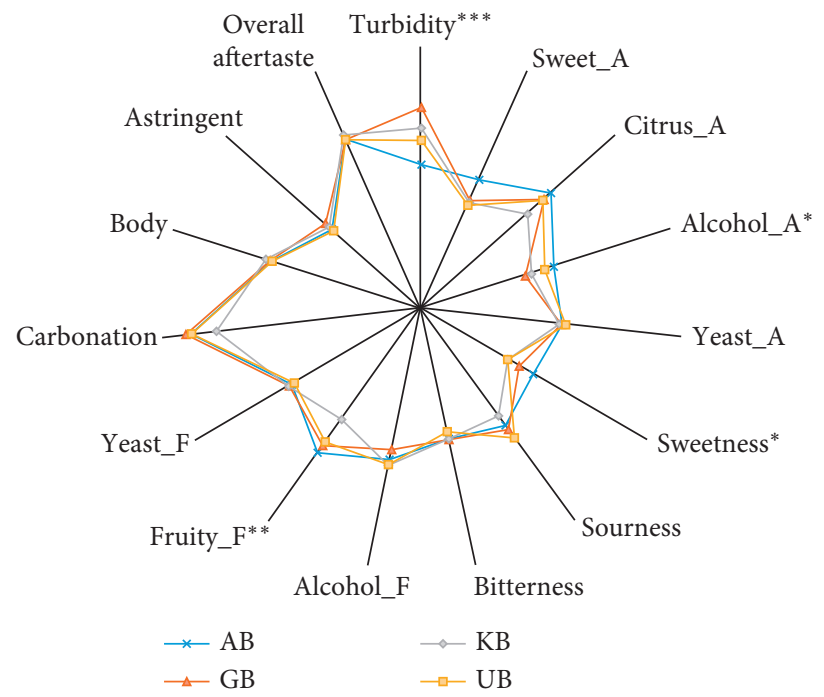

FIGURE 5: Sensory profiles of four beer samples by consumers $(n=102)$. GB, UB, KB, and AB represent wheat beers made of grist containing $50 \%$ of wheat malt from German, USA, and Korean wheat variety (Keumkang and Anzunbaengi), respectively. A: aroma; F: flavour; ${ }^{* * *} p<0.01,{ }^{* *} p<0.05$, and ${ }^{*} p<0.10$.

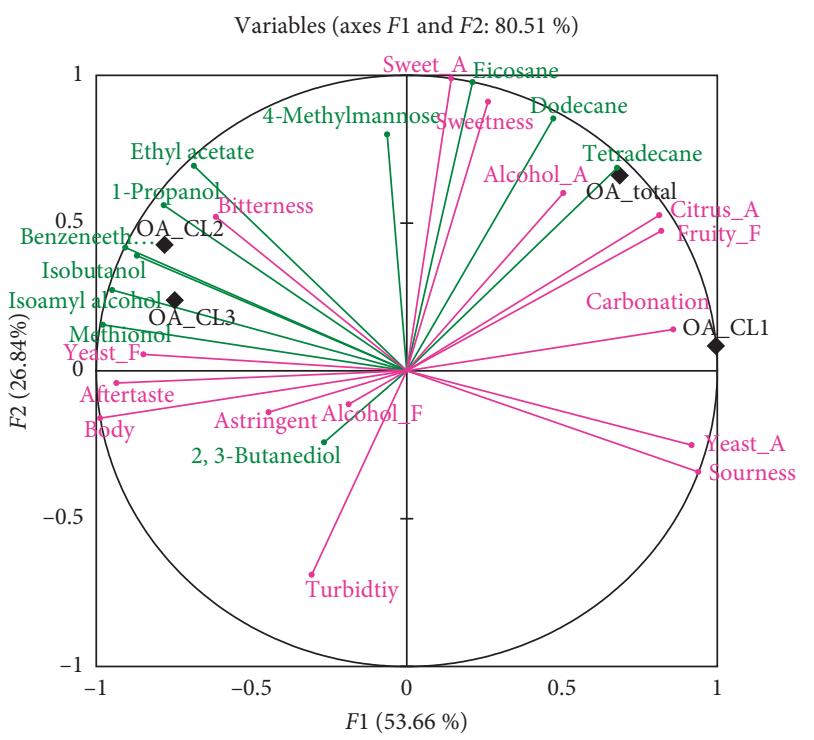

(a)

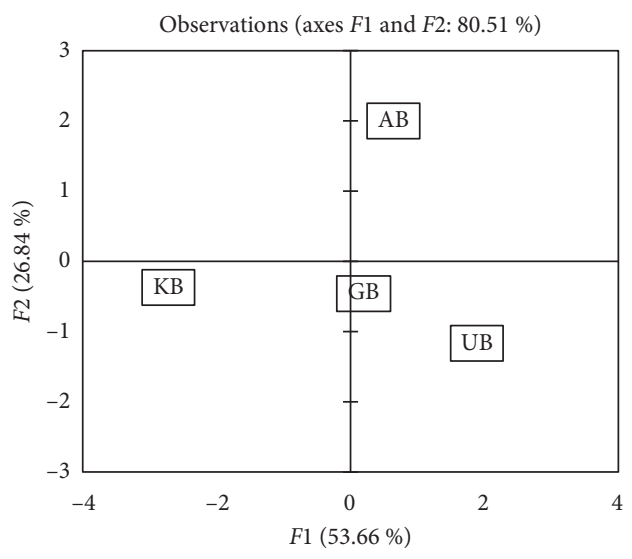

(b)

Figure 6: (a) Correlation map of volatile compounds (green), sensory attributes by 102 consumers (magenta; A: aroma, F: flavour), and overall acceptance (OA) of each consumer group by preference (cluster 1, 2, and 3; CL 1, 2, and 3) and total consumers (diamond). (b) Four wheat beer samples by first two dimension of multiple factor analysis. GB, UB, KB, and AB represent wheat beers made of grist containing $50 \%$ of wheat malt from German, USA, and Korean wheat variety (Keumkang and Anzunbaengi), respectively. 
According to the aforementioned AHC of overall consumer acceptability, CL2 was considered the beer-liking group, while CL3 had a middling preference for the samples; both CL2 and CL3 preferred KB. This is noteworthy, as it shows the obvious existence of a group far from the OA_total. This finding suggested the importance of selecting the target population for product development. Namely, although KB scored the lowest according to the OA_total, there might be consumer segments who prefer KB. However, this hypothesis is limited to understanding individual consumer groups, due to the insufficient number of participants to split into the grouping by preference trend. Additionally, the samples made were at the laboratory brewing scale. Therefore, further studies should be performed at an industry scale to generalize the beer brewing model and test consumer perceptions.

\section{Conclusions}

In this study, the aptness of Korean wheat varieties, Anzunbaengi and Keumkang, for wheat beer was investigated by analysing the characteristics of malt and beer making. The Korean wheat malt samples (AM and KM) made of the Anzunbaengi and Keumkang were compared with two other wheat malt samples (UM and GM) from the USA and Germany, which were used as control samples. The results of this study showed that most malt quality parameters satisfied the recommendations of EBC for beer brewing; these were generally similar, except for those factors related to protein. The Korean malt samples were higher in SN, TN, and FAN than the control malt samples. KM had a lower Kolbach index than the other malt samples. For the volatile compounds, the PLS-DA plot showed that the four wheat beers were discriminated by the 11 identified compounds with VIP values above 1.0. However, any compounds responsible for the discrimination of the four beer samples were not related to the sensory attributes perceived by the consumers $(n=102)$. The consumers preferred $\mathrm{AB}$ to $\mathrm{KB}$ in terms of appearance and flavour. They reported that $\mathrm{AB}$ was lower in turbidity and higher in alcohol aroma, sweetness, and fruity flavour than $\mathrm{KB}$. In terms of consumer acceptability, the overall acceptance was not significantly different among the four wheat beer varieties, but each consumer group by AHC clustering had a different trend to prefer beer products. This report is the first study to perform a comparative characterisation of Korean wheat malt with commercial ones for beer brewing. These might be useful to small breweries attempting to use Korean wheat malt and/or develop new distinctive local products. However, considering that this study was done by laboratory scale, variations in brewing conditions should be considered before applying these results directly to industries. Therefore, further research is required to apply these results at the industrial scale.

\section{Data Availability}

The data used to support the findings of this study are available from the corresponding author upon request.

\section{Conflicts of Interest}

The authors declare that there are no conflicts of interest regarding the publication of this paper.

\section{Authors' Contributions}

Han Sub Kwak and Sang Sook Kim contributed equally to this work.

\section{Acknowledgments}

This work was supported by the Main Research Program (E0211300-01) of the Korea Food Research Institute (KFRI) funded by the Ministry of the Science and ICT, Republic of Korea, and by the Korea Institute of Planning and Evaluation for Technology in Food, Agriculture, Forestry, Fisheries (IPET) through the Agri-Bio Industry Technology Development Program, funded by the Ministry of Agriculture, Food, and Rural Affairs (MAFRA) (grant no. 317019-4).

\section{Supplementary Materials}

Table S1: relationship among the quality indices from the malt to beer and volatile compounds in finished beer. (Supplementary Materials)

\section{References}

[1] D. E. Briggs, Malts and Malting, Springer Science \& Business Media, London, UK, London, 1998.

[2] H. Yin, J. Dong, J. Yu et al., "A preliminary study about the influence of high hydrostatic pressure processing on the physicochemical and sensorial properties of a cloudy wheat beer," Journal of the Institute of Brewing, vol. 122, no. 3, pp. $462-467,2016$.

[3] Z. Jin, B. Zhou, J. Gillespie et al., "Production of deoxynivalenol (DON) and DON-3-glucoside during the malting of Fusarium infected hard red spring wheat," Food Control, vol. 85, pp. 6-10, 2018.

[4] A. Paternoster, B. Jaskula-Goiris, B. De Causmaecker et al., "The interaction effect between vibrations and temperature simulating truck transport on the flavor stability of beer," Journal of the Science of Food and Agriculture, vol. 99, no. 5, pp. 2165-2174, 2019.

[5] A. Faltermaier, D. Waters, T. Becker, E. Arendt, and M. Gastl, "Common wheat (Triticum aestivumL.) and its use as a brewing cereal - a review," Journal of the Institute of Brewing, vol. 120, no. 1, pp. 1-15, 2014.

[6] Y.-H. Jin, J.-H. Du, K.-L. Zhang, and X.-C. Zhang, "Effects of wheat starch contents on malt qualities," Journal of the Institute of Brewing, vol. 117, no. 4, pp. 534-540, 2011.

[7] S. A. Depraetere, F. Delvaux, and F. R. Delvaux, "Wheat variety and barley malt properties: influence on haze intensity and foam stability of wheat beer," Journal of the Institute of Brewing, vol. 110, no. 3, pp. 200-206, 2004.

[8] P. Coghe, S. Salvi, A. Giomo, R. Van Deun, E. Boselli, and N. G. Frega, "Taste-active components of beers from Emmer Wheat (Triticum dicoccum) malt," Scientia Agriculturae Bohemica, vol. 47, no. 2, pp. 82-89, 2016.

[9] H. Mayer, O. Marconi, and G. Perretti, "Investigation of the suitability of hulled wheats for malting and brewing," Journal 
of the American Society of Brewing Chemists, vol. 69, no. 2, p. 120, 2011.

[10] O. Marconi, H. Mayer, F. Chiacchieroni, E. Ricci, G. Perretti, and P. Fantozzi, "The influence of glumes on malting and brewing of hulled wheats," Journal of the American Society of Brewing Chemists, vol. 71, no. 1, pp. 41-48, 2013.

[11] A. Bianco and F. Fancello, "Microbial communities and malt quality of durum wheat used in brewing," Journal of the Institute of Brewing, vol. 125, no. 2, pp. 222-229, 2019.

[12] Balmas and Liquor Industry Association, "Annual trade statistics," 2020.

[13] National Tax Service of republic of Korea, Current status of liquor shipments. Availabe online:https://www.index.go.kr, 2020.

[14] E. J. Baek, Y. A. Kwon, and K. W. Hong, "Adding enzymes to improve the properties of the Korean barley gwangmaek wort during mashing," Food Science and Biotechnology, vol. 25, no. 5, pp. 1387-1391, 2016.

[15] J. H. Kim and J. H. Kim, "Choi Multivariate analysis for feasibility of Korean six-row barleys for beer brewing," Journal of the Institute of Brewing, vol. 120, no. 4, pp. 371-378, 2014.

[16] S. K. Lee and H. Y. Park, "Choi Comparison of the quality characteristics of commercial barley malts in Korea," The Korean Journal of Food And Nutrition, vol. 31, no. 5, pp. 598-603, 2018.

[17] D. Shin, Y. Choi, and S. Jeong, "Quality characteristics of mixed makgeolli with barley and wheat," The Korean Journal of Food And Nutrition, vol. 29, no. 4, pp. 565-572, 2016.

[18] E. Sim, S. K. Lee, and K. S. Woo, "The quality characteristics of wheat-makgeolli made from different cultivars and milling rates," The Korean Journal of Food And Nutrition, vol. 29, no. 5, pp. 777-784, 2016.

[19] Y. S. Byeon, D. Lee, and Y. Hong, "Comparison of physicochemical properties and metabolite profiling using $1 \mathrm{H}$ NMR spectroscopy of Korean wheat malt," Foods, vol. 9, no. 10, p. 1436, 2020.

[20] European Brewing Convention, “Analytica-EBC," 2020, https://brewup.eu/ebcanalytica.

[21] S. Sadasivam and A. Manickum, Biochemical Methods, New age international publishers, New Delhi, India, 2nd edition, 2005.

[22] Association of Official Agricultural Chemists International, "AOAC Official Method," 2020, http://www.aoacofficialmethod. org/index.php?main_page=product_info\&products_id=340.

[23] P. Adadi, E. Kovaleva, and T. Glukhareva, "Production and analysis of non-traditional beer supplemented with sea buckthorn," Agronomy Research, vol. 15, pp. 1831-1845, 2017.

[24] L. F. Guido, P. G. Rodrigues, and J. A. Rodrigues, "The impact of the physiological condition of the pitching yeast on beer flavour stability: an industrial approach," Food Chemistry, vol. 87, no. 2, pp. 187-193, 2004.

[25] S. Vidal, L. Francis, and P. Williams, "The mouth-feel properties of polysaccharides and anthocyanins in a wine like medium," Food Chemistry, vol. 85, no. 4, pp. 519-525, 2004.

[26] C. Bamforth, Brewing: New Technologies, Woodhead Publishing Ltd, Cambridge, UK, 2006.

[27] M. J. Lewis and T. W. Young, Brewing, Springer Science \& Business Media, London, UK, 2012.

[28] I. Mascia, C. Fadda, and P. Dostálek, "Is it possible to create an innovative craft durum wheat beer with sourdough yeasts? a case study," Journal of the Institute of Brewing, vol. 121, no. 2, pp. 283-286, 2015.

[29] B. P. N. Phiarais, A. Mauch, and B. D. Schehl, "Processing of a top fermented beer brewed from 100\% buckwheat malt with sensory and analytical characterisation," Journal of the Institute of Brewing, vol. 116, no. 3, pp. 265-274, 2010.

[30] Y. R. Huang, J. Tippmann, and T. Becker, "Kinetic studies of main wort flavor compounds and iso-alpha-acids during wort boiling: a review," European Food Research and Technology, vol. 243, no. 9, pp. 1485-1495, 2017.

[31] I. Mascia, C. Fadda, and P. Dostálek, "Preliminary characterization of an Italian craft durum wheat beer," Journal of the Institute of Brewing, vol. 120, no. 4, pp. 495-499, 2014.

[32] N. Coote and B. Kirsop, "Factors responsible for the decrease in $\mathrm{pH}$ during beer fermentations," Journal of the Institute of Brewing, vol. 82, no. 3, pp. 149-153, 1976.

[33] I. M. Ferreira and L. F. Guido, "Impact of wort amino acids on beer flavour: a review," Fermentation, vol. 4, no. 2, p. 23, 2018.

[34] K. Yoshizawa, "On various factors affecting formation of isobutanol and isoamyl alcohol during alcoholic fermentation," Agricultural and Biological Chemistry, vol. 30, no. 7, pp. 634-641, 1966.

[35] K. Nordström, "Formation of esters, acids and alcohols from $\alpha$-keto acids by brewer's yeast," Journal of the Institute of Brewing, vol. 69, no. 6, pp. 483-495, 1963.

[36] C. G. Viejo, S. Fuentes, and D. D. Torrico, "Chemical characterization of aromas in beer and their effect on consumers liking," Food Chemistry, vol. 293, pp. 476-485, 2019.

[37] E. Coelho and J. Magalhaes, "Pereira volatile fingerprinting differentiates diverse-aged craft beers," $L W T$-food Science and Technology, vol. 108, pp. 129-136, 2019.

[38] P. G. Hill and R. M. Smith, "Determination of sulphur compounds in beer using headspace solid-phase microextraction and gas chromatographic analysis with pulsed flame photometric detection," Journal of Chromatography A, vol. 872, no. 1-2, pp. 203-213, 2000.

[39] E. D. Baxter and P. S. Hughes, Beer: Quality, Safety and Nutritional Aspects, RSC Publishing, Cambridge, UK, 2019.

[40] Y. Seow, P. K. C. Ong, and S. Liu, "Production of flavouractive methionol from methionine metabolism by yeasts in coconut cream," International Journal of Food Microbiology, vol. 143, no. 3, pp. 235-240, 2010.

[41] S. Zhuang, R. Shetty, and M. Hansen, "Brewing with $100 \%$ unmalted grains: barley, wheat, oat and rye," European Food Research and Technology, vol. 243, no. 3, pp. 447-454, 2017.

[42] J. Heo, H. S. Kwak, and M. Kim, "Major sensory attributes and volatile compounds of Korean rice liquor (yakju) affecting overall acceptance by young consumers," Foods, vol. 9, no. 6, p. 722, 2020.

[43] H. S. Kwak, J. F. Meullenet, and Y. Lee, "Sensory profile, consumer acceptance and driving sensory attributes for commercial vanilla ice creams marketed in the United States," International Journal of Dairy Technology, vol. 69, no. 3, pp. 346-355, 2016. 